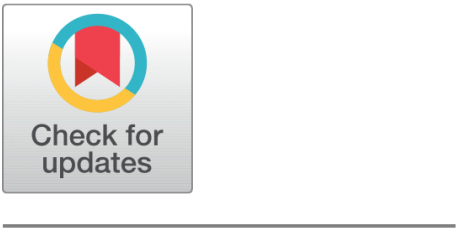

OPEN ACCESS

Received: 25.04.2021

Accepted: 19.05.2021

Published: 20.06.2021

Citation: Pavithra GS, Babu NV (2021) An Optimal Energy Utilization of Cluster Routing Protocol for Wireless Sensor Network in Restricted Area. Indian Journal of Science and Technology 14(22): 1813-1828. https://doi.org/ 10.17485/IJST/v14i22.671

* Corresponding author. pavi.pgs@gmail.com

Funding: None

Competing Interests: None

Copyright: (c) 2021 Pavithra \& Babu. This is an open access article distributed under the terms of the Creative Commons Attribution License, which permits unrestricted use, distribution, and reproduction in any medium, provided the original author and source are credited.

Published By Indian Society for Education and Environment (iSee)

ISSN

Print: 0974-6846

Electronic: 0974-5645

\section{An Optimal Energy Utilization of Cluster Routing Protocol for Wireless Sensor Network in Restricted Area}

\author{
G S Pavithra ${ }^{1 *}$, N V Babu ${ }^{2}$ \\ 1 Research Scholar, Department of CSE, SJB Institute of Technology, Bengaluru, 560060, \\ Karnataka, India \\ 2 Professor \& HoD, Department of EEE, SJB Institute of Technology, Bengaluru, 560060, \\ Karnataka, India
}

\section{Abstract}

Objectives: To efficiently monitor the highly confined area by using security measurement methods to enhance the lifetime of a large area coverage network. Methods : the modified nodes are included in the normal execution process of the network to calculate the efficiency and lifetime of the WSN. With the help of the simulation and analysis process, the proposed protocol is found to be more powerful to impact the sustainability of the network by prolonging the lifetime of the nodes. To perform this operation, the following parameters are considered: Area of the monitoring area, Number nodes, Sink portion, Energies of radio amplifier systems, Data aggregation, node electronics, and data packet length. Findings: The proposed optimal energy cluster routing protocol finds the best topological structural protocol to select the cluster head with optimal connectivity path with other nodes in a group. The data of energy utilization, data communication rate between nodes and cluster head, and analysis of the number of alive nodes concerning time are obtained. Novelty: the proposed Optimal efficient cluster routing protocol (OECRP) selects the cluster head by considering energy consumption, cluster sustainability, and its proper communication with other nodes. OECRP is used to develop the optimal topological structural protocol to connectivity path with other nodes in a group.

Keywords: Heterogeneous network; Lowenergy adaptive clustering hierarchy (LEACH); optimal efficient cluster routing protocol (OECRP); Network lifetime; Cluster head selection

\section{Introduction}

In recent times, Wireless Sensor Networks (WSN) is in many sectors like military, environmental monitoring, medical surveillance, underwater, etc., where human activities are minimal. Figure 1 shows recent applications in wireless sensor network communication process in the particular qualities of the underground climate. A group of micro sensor nodes constitute a wireless sensor network and are deployed in a particular area with at least one sink or base station. 


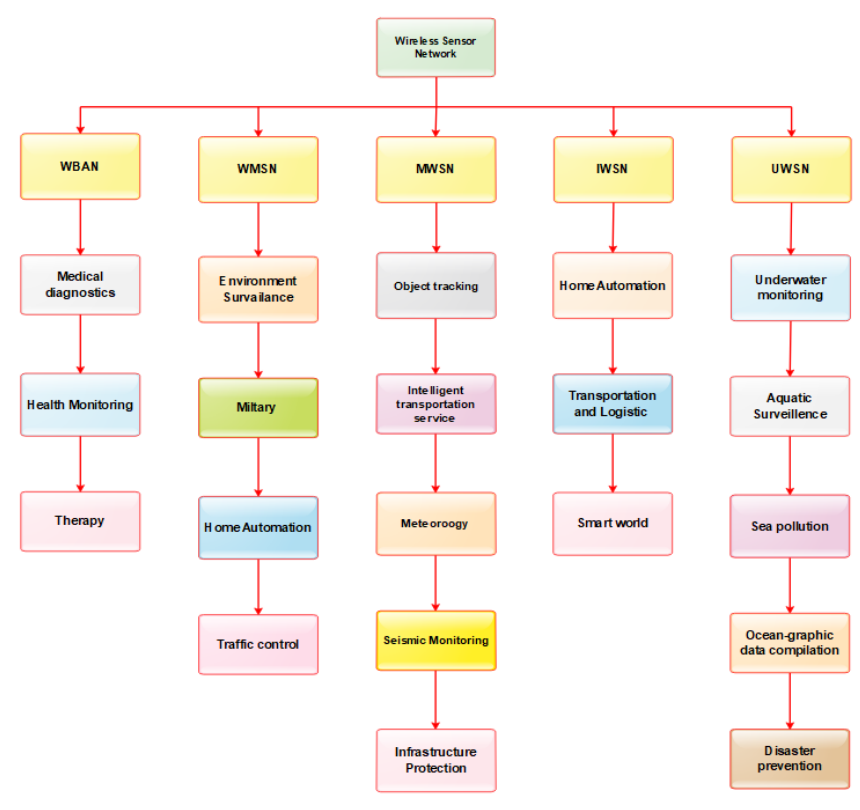

\begin{tabular}{|l|l|l|} 
WBAN=Wireless Body Area Network & WMSN=Wireless Multimedia Sensor Network & MWSN=Mobile Wireless Sensor Network \\
\hline
\end{tabular}

IWSN=Industrial Wireless Sensor Network $\quad$ UWSN=Underwater Wireless Sensor Networks

Fig 1. Wireless sensor network application

In the wireless sensor network, there are different kinds of sensor nodes which include source sensor node (normal node), intermediate sensor nodes (cluster head), and base station ${ }^{(1-3)}$ as shown in Figure 2.

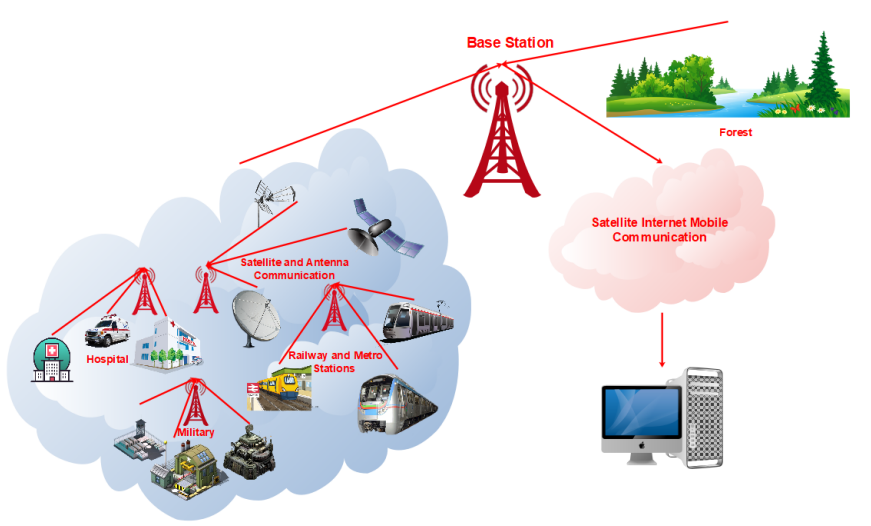

Fig 2. Fundamental communication process in wireless sensor network

\subsection{Research Gaps}

This micro sensor nodes monitor the environmental and physical parameters like heartbeat, temperature, pollution and so on. The sink gets the data from the sensor node devices and then sends it to the user through cluster heads. The energy consumption is due to data collection, processing, transmitting, or receiving of the packets. From the observations, energy consumption is the major constraint in a wireless sensor network. In addition to this, the redundancy of data also contributes to a decrease in energy efficiency. Increasing the network lifetime with an economical energy supply is a challenge for the wireless sensor network. Many studies on wireless sensor network in this aspect is gaining importance and establishes the importance of routing protocols. A 
remote communication system technology in a restricted underground zone is fundamentally impacted on unconventional channel distribution features. Karpagam introduces a methodology of a model radio wave distribution or propagation in 3.2 $\mathrm{GHz}$ and $6.0 \mathrm{GHz}$ of frequency groups appears in form of narrow curve shape decoration in multiple aspects ${ }^{(4)}$. Gomathi et al. introduced a model of consists a signal to noise ratio it is called Propagation Path Loss (PL) that portrays the loss of power against distance among transmitter and beneficiary for a passage climate ${ }^{(5)}$. T. Priya et al. introduced a Structure Aware Self Adaptive (SASA) wireless framework in the observation of underground coal mineshaft ${ }^{(6)}$. On controlling lattice sensor network sending and planning a collective system dependent on a customary guide procedure. SASA had the option of quickly identifying primary varieties brought out by underground breakdowns ${ }^{(5-7)}$. A model has been sent with 29 mica- 2 motes in genuine coal mineshaft. It made a huge scope follow-driven recreation given genuine data gathered from the trials. A new taxonomy of leach descendant protocols has been proposed in this research work. The work concentrates on CH Selection and techniques to transfer data to classify LEACH variant protocols. Figure 3 depicts the taxonomy of leach-based routing protocols.

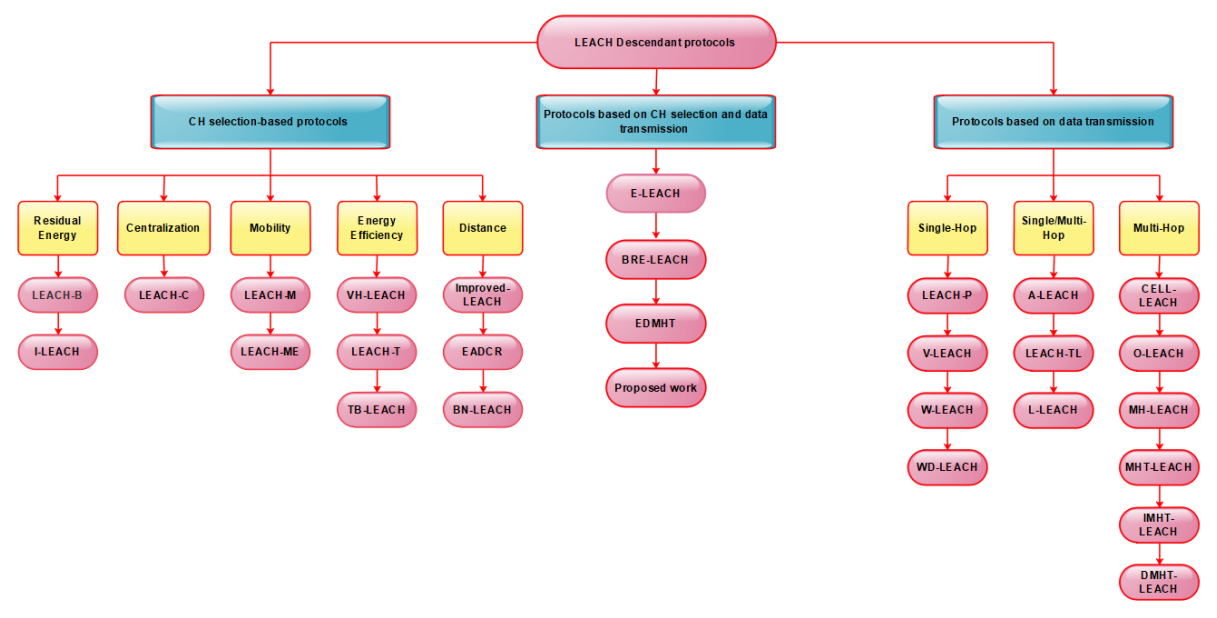

Fig 3. Taxonomy of various LEACH protocols in a wireless sensor network.

\section{Energy Model}

Let us consider the $\mathrm{N}$ distributed nodes in an $\mathrm{A}^{\star} \mathrm{A}$ zone and utilized a mathematical model of fundamental WSN energy dissipation of hardware that appeared in ${ }^{(8)}$. The communication between source and destination through wireless sensor network in a free space and the multiple way blurring (fading attenuation of signals) models framework as per the distance among transmitter and beneficiary (receiver), it means $r^{2}$ (power loss in free space) and $r^{4}$ (multiple ways fading) ${ }^{(9)}$. The amount of energy utilized in the transmission of 1 bit data over a distance of a $d$ is equivalent to Equation.1, considering energy distributed from a transmitter to operate the radio-based devices and power amplifiers, etc. Furthermore, to get this data, the receiver distributed a specific quantity of energy equivalent to Equation.2.

$$
\begin{gathered}
E_{T}(i, r)=\left\{\begin{array}{ll}
i E_{e}+i \varepsilon_{f_{s}} r^{2} & r<r_{0} \\
i E_{e}+i \varepsilon_{m p} r^{4} & r \geq r_{0}
\end{array}\right\} \\
E_{R}(i)=i E_{e}
\end{gathered}
$$

Where $E_{e}=$ electronics energy. $\varepsilon_{f s}$ and $\varepsilon_{m p}$ are the energies of radio amplifiers in various systems. Moreover, the nodes of the sensor consume $E_{\text {Dagg }}\left(\mathrm{nJ} / \mathrm{bit} /\right.$ signal) quantity of energy in case of information aggregation ${ }^{(10)}$.

\section{OECRP Protocol}

Usually, the cluster head utilizes the amount of energy that is greater than the member nodes. To stay away from the prior death of the node, the overall node in a network revolves to act as a cluster head. Along these lines, calculation incorporates a setup 
stage with a consistent stage in every circle ${ }^{(11)}$. Choice of routing tree and also cluster head development between the clusters head are operated in the setup stage. At a steady stage, the information is transferred from member nodes to a relating cluster head, at that point the cluster head will going to aggregate the necessary information and forward it to the parent node and up to the root nodes. Here, at that point, the root node will communicate with the base station straight forwardly.

\subsection{Selection of Cluster Head}

This part gives some brief details regarding our OECRP convention methods. An OECRP utilizes the overall left-over energy of node and normal energy levels of a network to choose a cluster head. Here $p_{\text {optimal }}$ is the cluster head optimal proportionality variable ${ }^{(12-14)}$. Here, we have utilized $n_{k}$ to represent the quantity of the circles that are required for the cluster head in a node $A_{s}$ and we also refer to this as a revolving epoch. To ensure the average of $p_{\text {optimal }}$ cluster heads each round, let every node $A_{s}(\mathrm{k}=1,2,3, \ldots \ldots \mathrm{N})$ turn into a cluster head once for each $n_{k}=\frac{1}{p_{\text {optimal }}}$ adjusts. By our OECRP convention, we consider various estimations of $n_{k}$ depending on the remaining energy $E\left(C_{r}\right)$ of a node $A_{s}$ at around ' $C_{r}^{\prime}$. Let the $p_{k}=\frac{1}{n_{k}}$, it can also be additionally viewed as an average probability in case of cluster head during $n_{k}$ rounds. Here we utilized $E\left(C_{r}\right)$ for the indication of required energy at round ${ }^{\prime} C_{r}^{\prime}$ for a network, that can be processed by Equation 3.

$$
\bar{E}\left(C_{r}\right)=\frac{1}{N} \sum_{k=1}^{N} E_{k}\left(C_{r}\right)
$$

We have given an estimation of $E\left(C_{r}\right)$ here to minimize the financial expenditure of calculation. In an event that absolute rounds of a lifetime of the network are known, here it is possible from our side to estimate the normal energy of every round in a network ${ }^{(15-17)}$. Most importantly, it is necessary to analyze the network lifetime $L_{t}$ that is the complete iterations. $E_{S u m}$ is the network energy at the initial energy state. Under the ideal condition, every node passes on simultaneously. $E_{\text {iteration }}$ will remains the same in every round in case of energy cost equivalent. $L_{t}$ is known from the estimated Equation 4.

$$
L_{t}=\frac{E_{\text {Sum }}}{E_{\text {iteration }}}
$$

With a model of energy given in part 2, overall energy which is distributed across the network in a single cycle is represented as follows

$$
E_{\text {iteraion }}=i\left(2 N E_{e}+N E_{\text {Dagg }}+C_{n} \varepsilon_{m p} r_{C H t o B S}^{4}+C_{n} \varepsilon_{f s} r_{M N t o C H}^{2}\right)
$$

Where ' $\mathrm{i}$ ' is quantity of cluster, $E_{\text {Dagg }}$ data aggregation cost consumed in the cluster head, $r_{C H t o B S}$ is the normal separation among cluster head and base station, $r_{M N t o C H}$ will be normal separation among member node and cluster head ${ }^{(18,19)}$. With an assumption of uniformly distributed nodes, Equation .6 can be formed.

$$
r_{M N t o C H}=\frac{A}{\sqrt{2 \pi i}}, r_{C H t o B S}=0.776 \frac{A}{2}
$$

With a setting of a subsidiary of $E_{\text {iteraion }}$ regarding when 'i' $=0$, at that point we use an ideal number of cluster heads as Equation. 7.

$$
i_{\text {optimal }}=\frac{\sqrt{N}}{\sqrt{2 \pi}} \frac{\sqrt{\varepsilon_{f s}}}{\sqrt{\varepsilon_{m p}}} \frac{A}{r_{C H t o B S}^{2}}
$$

Bringing both the equations (6) and (7) in (5), we have acquired an energy $E_{\text {iteraion }}$ distributed in a single cycle. Along these lines, we can process the lifetime $L_{t}$ with equation 4 .

Accepting that every node utilizes energy in every round consistently, the average energy of the $r^{t h}$ iteration is stated as

$$
\bar{E}\left(C_{r}\right)=\frac{1}{N} E_{\text {sum }}\left(1-\frac{C_{r}}{L_{T}}\right)
$$

Utilizing the reference energy $\bar{E}\left(C_{r}\right)$, we can get Equation. 9.

$$
p_{k}=p_{\text {optimal }} \frac{\bar{E}_{k}\left(C_{r}\right)}{\bar{E}\left(C_{r}\right)}
$$


In which $p_{\text {optimal }}$ is the number optimal proportional cluster head. We are utilizing $p_{k}$ as a probability threshold rather than $p_{\text {optimal }}$ and afterward utilize every node $S N_{k}$ to decide for the cluster head or not in every cycle ${ }^{(20,21)}$. Hence the value of the threshold level can be known from the Equation. 10.

$$
\begin{gathered}
T\left(S N_{k}\right)=\left\{\begin{array}{cc}
\frac{p_{k}}{\left.1-p_{k\left(c_{r} m o d\right.} \frac{1}{p_{k}}\right)} & S N_{k} \in G \\
0 & \text { Others }
\end{array}\right\} \\
\delta_{k}=\frac{1}{p_{k}}=\frac{\bar{E}\left(C_{r}\right)}{p_{\text {optimal }} E_{k}\left(C_{r}\right)}=\delta_{\text {optimal }} \frac{\bar{E}\left(C_{r}\right)}{-E_{k}\left(C_{r}\right)}
\end{gathered}
$$

Equation 11 describes nodes with a large amount of remaining energy along with its more probability to turn into a cluster head more than the lesser ones. With Equation 9, here we can observe that the $p_{\text {optimal }}$ is the reference value of a probability $p_{k}$, that decides the revolving epoch $\delta_{k}$ and edge $T\left(S N_{k}\right)$ of the node $S N_{k}$. From a homogenous network, every node is outfitted with a similar starting energy, along these lines, the nodes utilize the same $p_{\text {optimal }}$ values as a reference point of the $p_{k}$. At the point when the network is heterogeneous, the values of reference of every node must vary regarding starting energy. In the case of a heterogeneous network, we have replaced the value of reference $p_{\text {optimal }}$ with a mass probability stated in equation.12.in the case of the normal and extraordinary node as Standard election protocol (SEP) convention ${ }^{(22-26)}$.

$$
p_{\text {normal }}=\frac{p_{\text {optimal }}}{1+\alpha \beta}, p_{\text {Special }}=\frac{p_{\text {optimal }}(1+\alpha)}{(1+\alpha \beta)}
$$

In which $\beta$ is a special node fraction and also that's energy can be considered as an $\alpha$ time greater than normal ones. Hence $p_{k}$ in an equation 9 becomes

$$
p_{k}=\left\{\begin{array}{ll}
\frac{p_{\text {optimal }} \overline{E_{k}}\left(C_{r}\right)}{(1+\alpha \beta) \bar{E}\left(C_{r}\right)} & , \text { Normal Node } \\
\frac{p_{\text {optimal }}(1+\alpha) \overline{E_{k}}\left(C_{r}\right)}{(1+\alpha \beta) \bar{E}\left(C_{r}\right)} & , \text { Special Node }
\end{array}\right\}
$$

Putting Equation 13 in 10, the probability of the threshold value $T\left(S N_{k}\right)$ can be known that can be utilized to choose a cluster head. At that point, the value of the threshold is straightforwardly associated with an initial and leftover energy of every node.

The selection of threshold edge $T\left(S N_{k}\right)$ has been utilized to choose that the node $S N_{k}$ will be cluster head. Furthermore, the $D_{\text {threshold }}$ is the threshold distance in Equation 14 that has been included. Hence, in the case of distance among the existing cluster head and node was not as much as $D_{\text {threshold }}$, at that point the node couldn't be chosen as a cluster head. This behavior optimizes the cluster strategy effectively.

$$
D_{\text {threshold }}=\frac{\sqrt{A_{s}}}{N * p_{k}}
$$

Where $\mathrm{N}$ is the number of sensor nodes, $p_{k}$ is the small portion of cluster head $A_{s}$ is the area size to be observed,

\subsection{Routing Tree}

During information transmission, once after cluster arrangement, it broadcasts the message of mass in a coverage zone of a $2 D_{\text {threshold. }}$ An ID of nodes and also weight $\mathrm{W}$ was remembered for a message. At that point each cluster head has been contrasted to its weight and gained one in a weighted message, afterwards, the nodes with the greatest weight have been chosen as a parent node. A node of more modest weight at that point will be going to send a child message to a parent node and afterward, the node of maximum weight has been chosen as a root node in a routing tree. In an event that the node didn't get any messages about the child message or weight, it demonstrates as there will be none of the cluster heads across it. Hence it must speak along with those kinds of base station straightforwardly. Figure 4 represents the cluster plan of the OECRP convention. Here $\mathrm{V}-\mathrm{Z}$ signifies both the cluster head and weight in a section. The Node $\mathrm{Z}$ receives the Weight message of the nodes V, W, X, Y, and it going to pick node W as its parent node. Similarly, node V and Y pick node Z as their parent 
node ${ }^{(27-29)}$. Node $\mathrm{X}$ will pick node $\mathrm{W}$ as its parent node. Moreover, the heaviness messages of $\mathrm{X}$ and $\mathrm{Z}$ are obtained from $\mathrm{W}$ are comparatively lower than the own one, hence $\mathrm{W}$ speaks along with a base station straightforwardly. Convention of OECRP develops directing tree which is appeared in Figure 4.

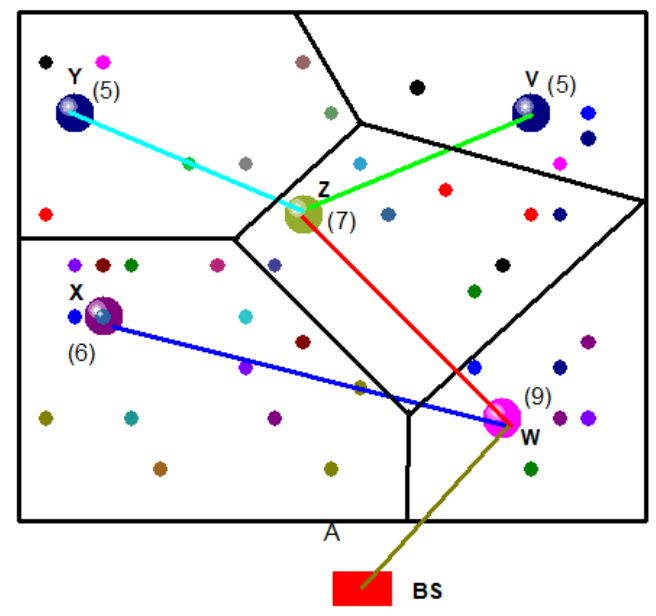

Fig 4. Fundamental structure of OECRP cluster

Left-over energy across the node and also separation among the node and base station have been considered for the weight calculation.

$$
W_{k}=\frac{E_{k}\left(C_{r}\right)}{E_{p r i} * R S I I}
$$

In which $E_{P r i}$ is primary energy and $R S I I$ is a received signal intensity identifier. Towards the starting of the complete network, values of RSSI are gained from communicating the signal testing of a base station ${ }^{(30-33)}$. Consequently, cluster heads that are nearer to a base station and having a sufficient amount of energy will have a high need to turn into the root node. At the point when two nodes having a similar weight, the parental node must be chosen from the IDs of the node ${ }^{(34)}$.

\section{Results and Discussion}

Here, we have implement the developed protocol of OECRP using NS2. The overall simulation results have tabulated in Table 1. The network topology produced from LEACH and OECRP conventions has appeared in Figures 5 and 6. Normally nodes of cluster head across OECRP have been conveyed all consistently since they considered that the distance is constrained for the optimization of cluster strategy.

Table 1. Criteria's for performance analysis

\begin{tabular}{ll}
\hline Criteria & Range \\
\hline Area of monitoring Range $(\mathrm{m})$ & $(0,0)-(100,100)$ \\
Number of nodes & 150 \\
Sink position & $(60,180)$ \\
$\varepsilon_{f s}\left(p j / b i t / m^{2}\right)$ & 10 \\
$\varepsilon_{m p}\left(p j / b i t / m^{2}\right)$ & 0.0016 \\
$\varepsilon_{e}(n j / b i t s)$ & 60 \\
$E_{\text {Dagg }}(n j)$ & 10 \\
$E_{O}(J)$ & 0.8 \\
Data packet length (Bytes) & 550 \\
\hline
\end{tabular}




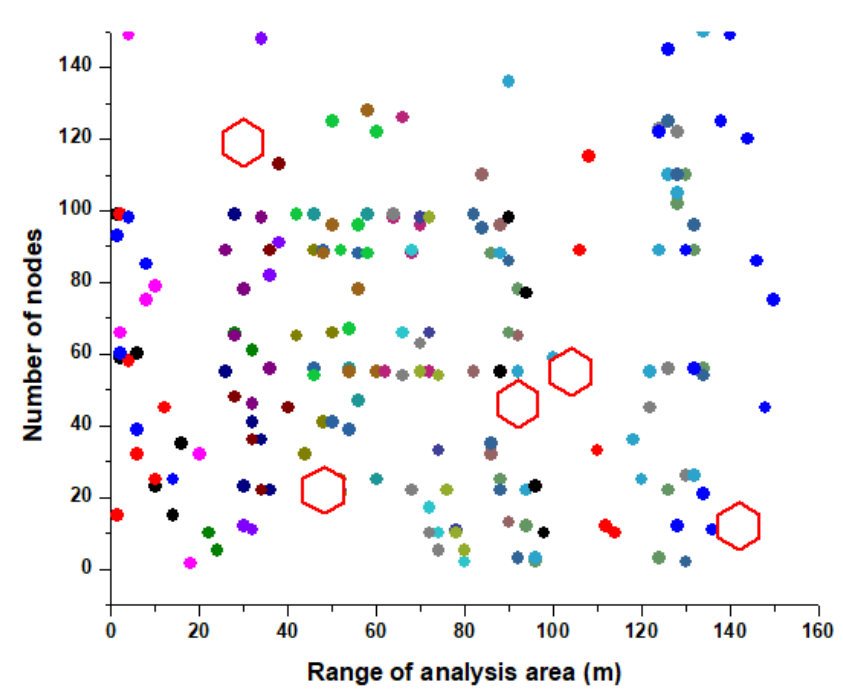

Fig 5. Conventional LEACH topology structure.

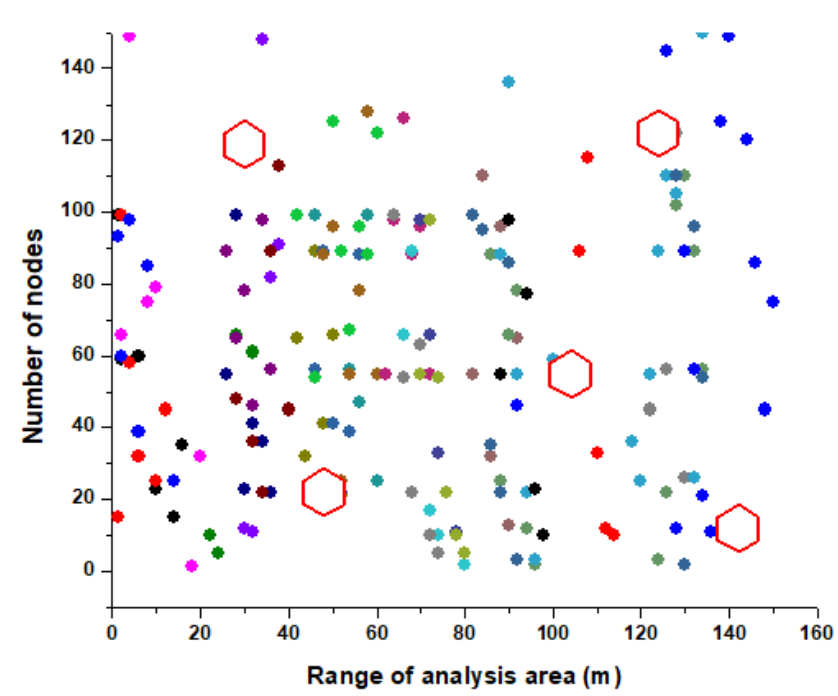

Fig 6. Proposed OECRP topology structure.

\subsection{Comparison of OECRP and LEACH in the Heterogeneous Network}

\subsubsection{Variety of $\alpha$ and $\beta$}

The primary energy of an ordinary node will be $0.6 \mathrm{~J}$. Here we replaced the beginning essential energy of an extraordinary node and also the quantity of the unique node under changing the estimation of $\alpha$ and $\beta$. Later the protocol is simulated and also analyzed the variation of the network lifetime ${ }^{(35-38)}$.

With Figures 7 and 8 , it is clear that it accurately shows the time interval for the survival of a network using a different kind of $\alpha$ and $\beta$. At a point when a negligible portion of the exceptional node is expanded in a range of 0.1 to 1 , as demonstrated in Figures 6 and 7, we can notice that the filter doesn't take benefits of the expanding complete energy brought about by modification of $\alpha$ and $\lambda$. These manage every node similarly and don't consider the quality of the heterogeneous energy. Along with the Contraction of LEACH, the OECRP convention can completely consider the distinction of energy on the time of cluster head selection. The lifetime of the network expands too rapidly along with the node's energy. In this way, the presentation of an OECRP convention is superior to the LEACH. 


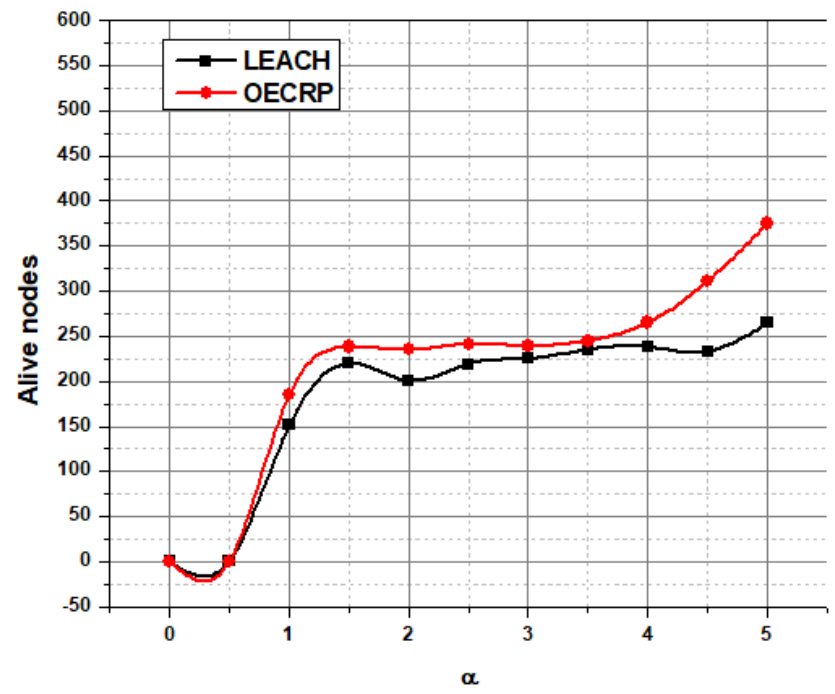

Fig 7. Network lifetime concerning $\alpha$

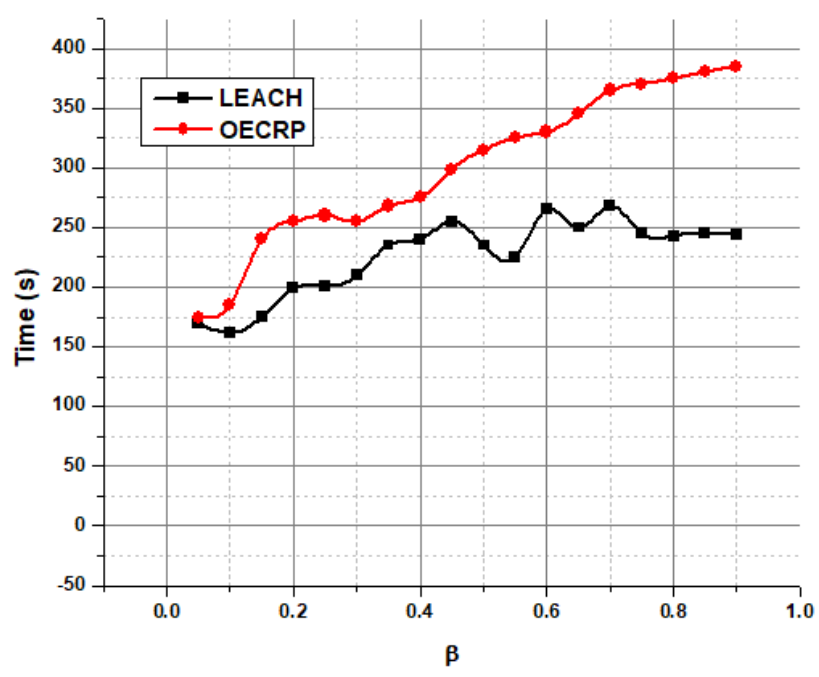

Fig 8. Network lifetime concerning $\beta$

\subsubsection{Fixed $\alpha$ and $\beta$}

Here we have completed some similar analysis using the exact values of the $\alpha$ and $\beta$ to reach the differences in performance among LEACH and OECRP. From Figure 9, the connection has been introduced among the lifetime of the network and quantities of a live node at the values of $\alpha=1.8, \beta=0.3$. We have seen the time that the principal node which kicked the bucket and an hour of an ending node in OECRP convention happened after that in filter convention ${ }^{(39,40)}$.

The explanation will be that the OECRP convention is not just considered for choosing nodes that have more remaining energy to be cluster heads, yet additionally brings into thought the requirement of separation which improves the cluster scheme of the cluster.

Also, at the time of transmission of information, the development of a routing tree between every cluster head can adjust the energy utilization of the cluster head ${ }^{(41,42)}$. 


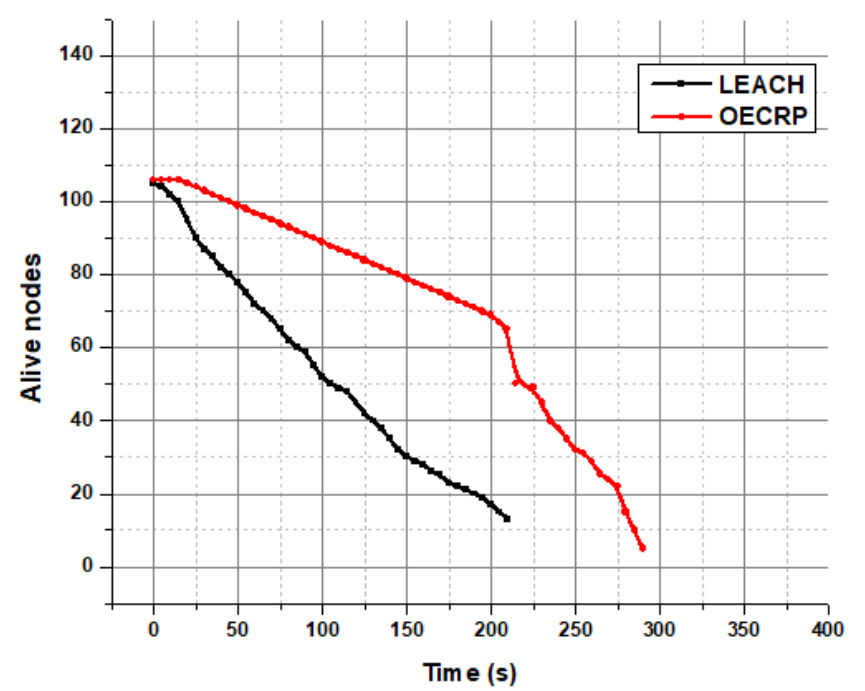

Fig 9. Synchronization between the number of alive nodes and network lifetime

\subsection{Comparison of OECRP and LEACH in the Homogenous Network}

\subsubsection{In $150 \mathrm{~m} \times 150 \mathrm{~m}$ monitoring area}

Here, the simulation has been done in these two kinds of protocols through the homogenous network and also made an examination of the network lifetime. The starting energy of every node will be $0.8 \mathrm{~J}$. Figure 10 represents the lifetime of 150 nodes in a LEACH and OECRP convention while comparing the number for Figure 11 is 250 . By this diagram, it is observed that the network lifetime of an OECRP is more than LEACH. Also, the difference between the lifetime curve of LEACH and OECRP is that the OECRP lifetime curve improves with the thickness of the node. This shows that OECRP thinks about the current remaining energy of nodes and the separation among cluster heads to upgrade the cluster strategy all the while, that not just adjusts just only load but also adjust energy utilization but additionally improves the network lifetime ${ }^{(43,44)}$.

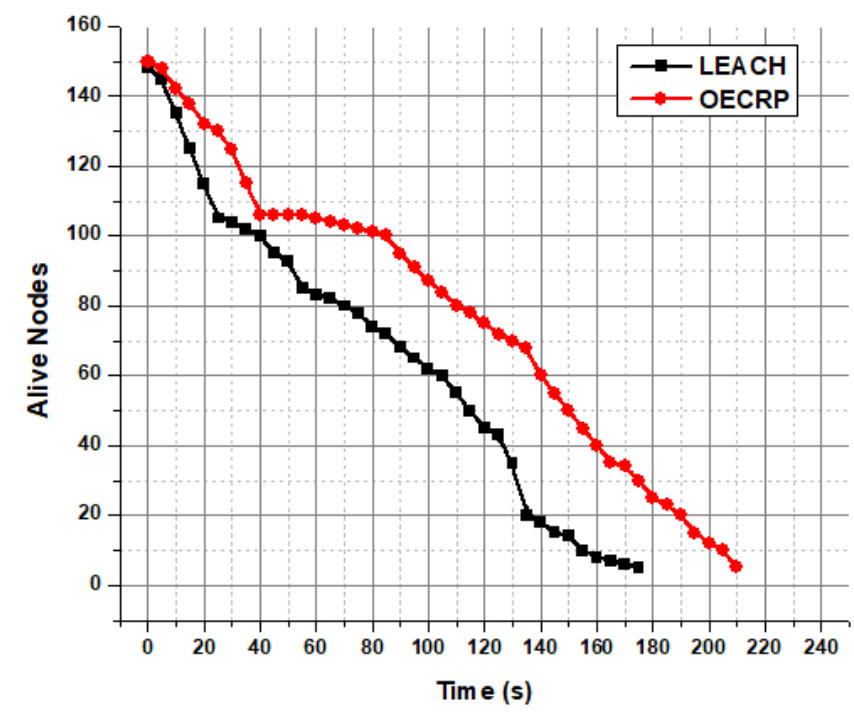

Fig 10. Network efficiency for 150 nodes concerning time 


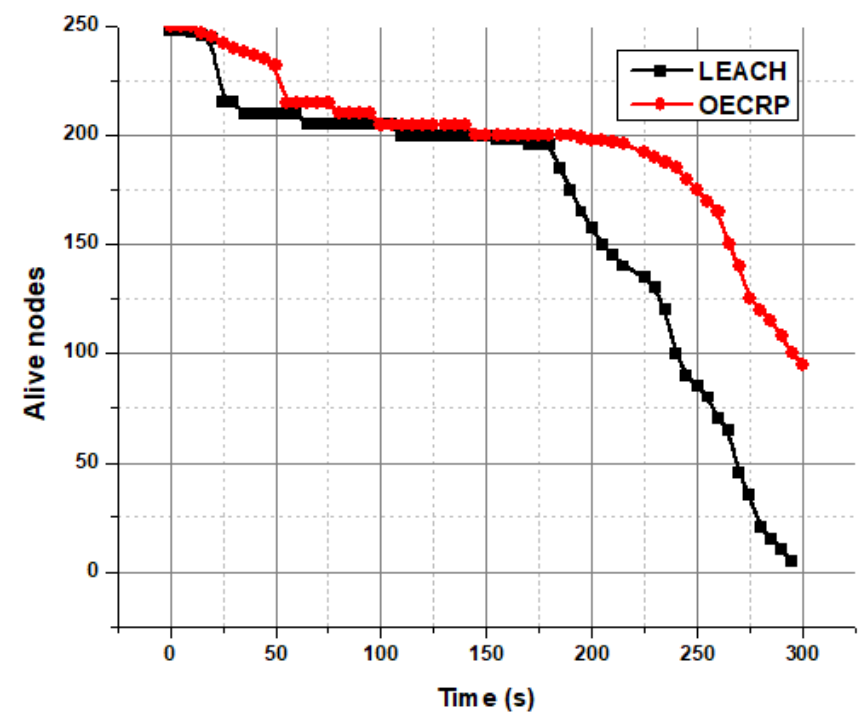

Fig 11. Network efficiency for 200 nodes concerning time.

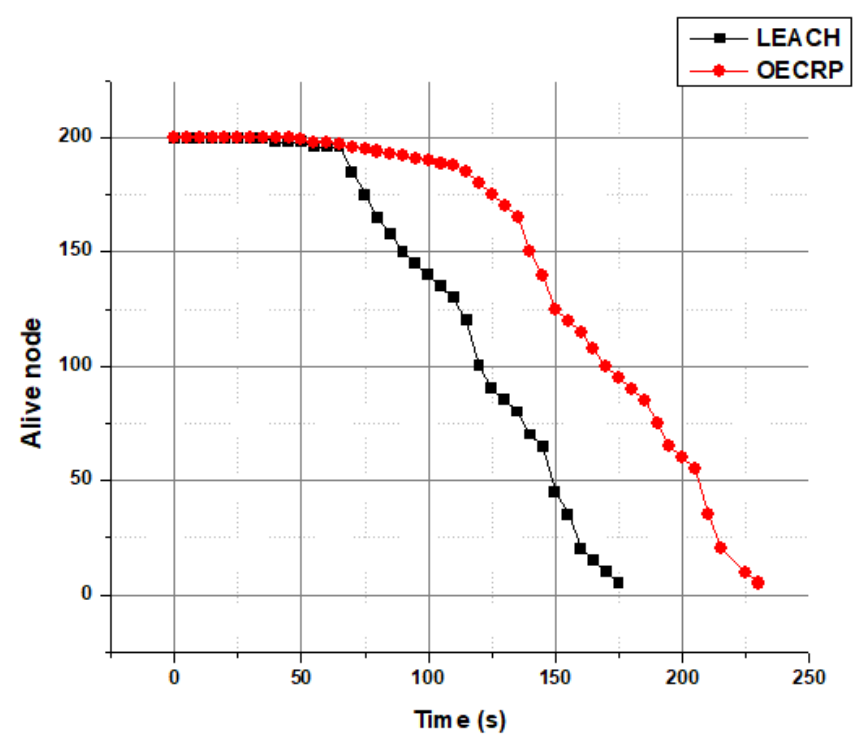

Fig 12. Network efficiency for 200 nodes concerning the time

\subsubsection{In $200 m \times 200 m$ monitoring area}

Here, the simulation has been done in these two kinds of protocols through the homogenous network and also made an examination of the network lifetime. The starting energy of every node will be $0.8 \mathrm{~J}$. Figure 12 represents the lifetime of 200 nodes in a LEACH and OECRP proposed method ${ }^{(45)}$.

\subsubsection{In 250m x 250m monitoring area}

From the above, every node starts with the underlying energy of $2 \mathrm{~J}$. We have simulated the conventions with various measures of nodes. The results of a simulation are shown in Figures 13 and 14 respectively. Those curves tend to 50, 150, 250, 350, 450, and 550 nodes. Individually, under the quantity of nodes 250 , the behavior of conventions is superior to others that leads to one of the conclusions in which the thickness of nodes will move up in a region with an increment of several nodes. Moreover, it builds up an impedance between nodes, that impacts the transmission of information, utilization of huge energy, and tends to 
the death eerier than the expectation.

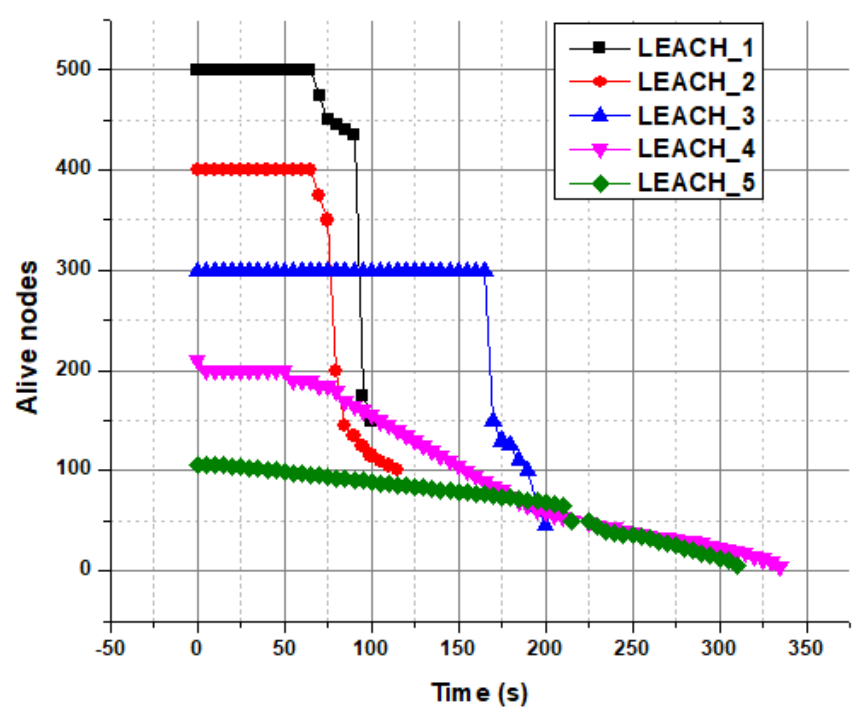

Fig 13. Various range of nodes lifetime using LEACH

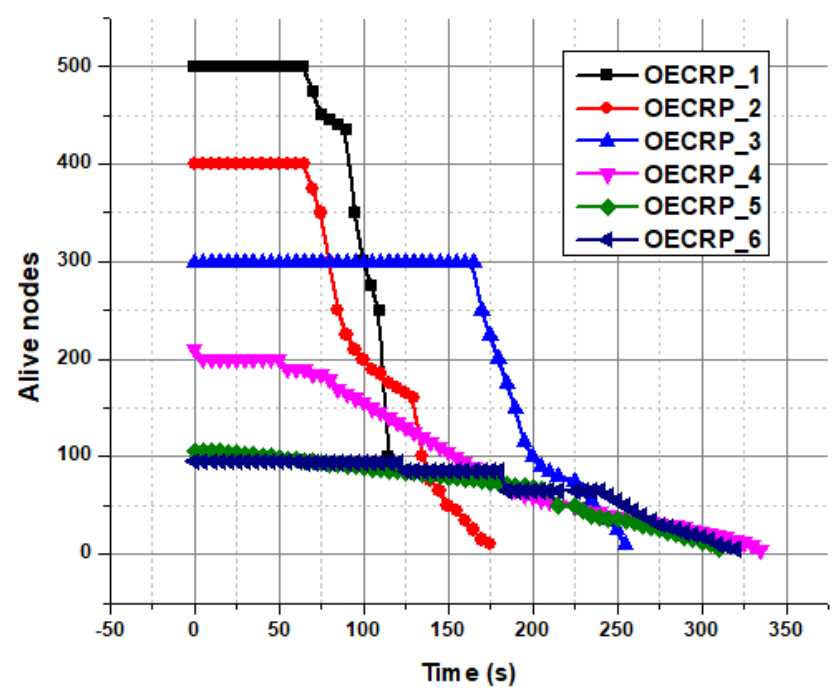

Fig 14. Various range of nodes lifetime using OECRP

Thus, it utilizes excess energy as transmission and reduces the lifetime of nodes. From Figures 13 and 14, it is clear that every curve represents the behavior of OECRP and also that will be superior to its LEACH counterpart. Through the instance of OECRP and nodes, death time is after that in LEACH, regardless of it is the starting node or the ending one. One of the reasons is OECRP thinks about the leftover energy of the nodes and the requirement of the distance between the cluster heads. This gives rise to the arrangement of nodes is more uniform, which makes the utilization of the energy all the more even also, minimizes the energy lost, and extends out the lifetime of the system ${ }^{(46-48)}$.

\subsubsection{Comparison of LEACH, LEACH-C, and OECRP}

Here we have simulated the overall behavior of LEACH, LEACH-C, and OECRP for the number of 60, 200, 300 nodes at the time of base station in the location of $(60,60)$ in this work. A LEACH-C selects the cluster head as per global guidelines. The creation of a cluster head carries with the topological placement of the node itself and separation by the base station. That will 
enhance the rule of LEACH-C conveniently.

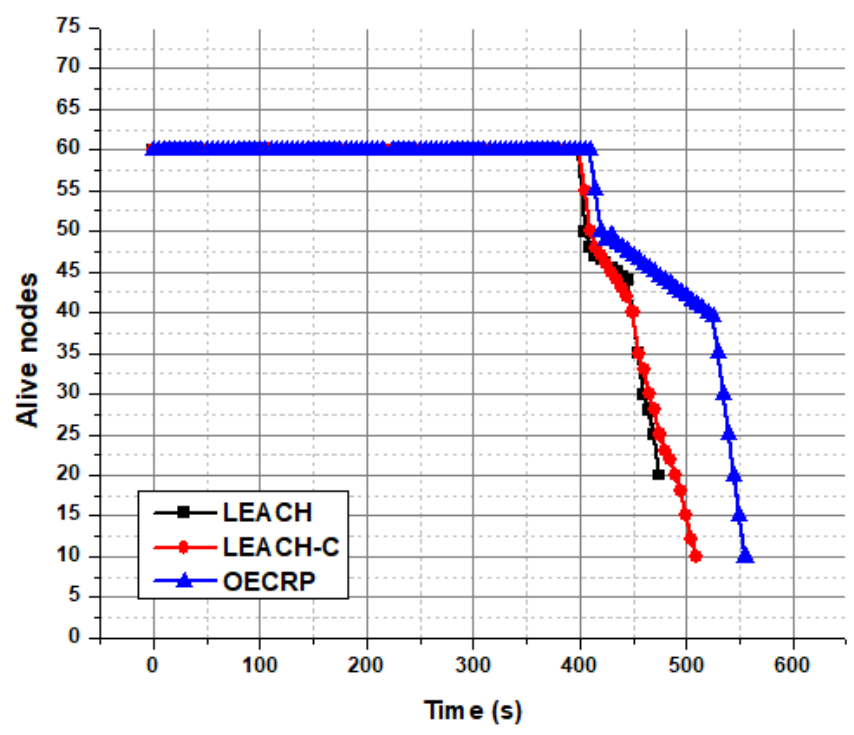

Fig 15. Network lifetime of three methods concerning 60 nodes.

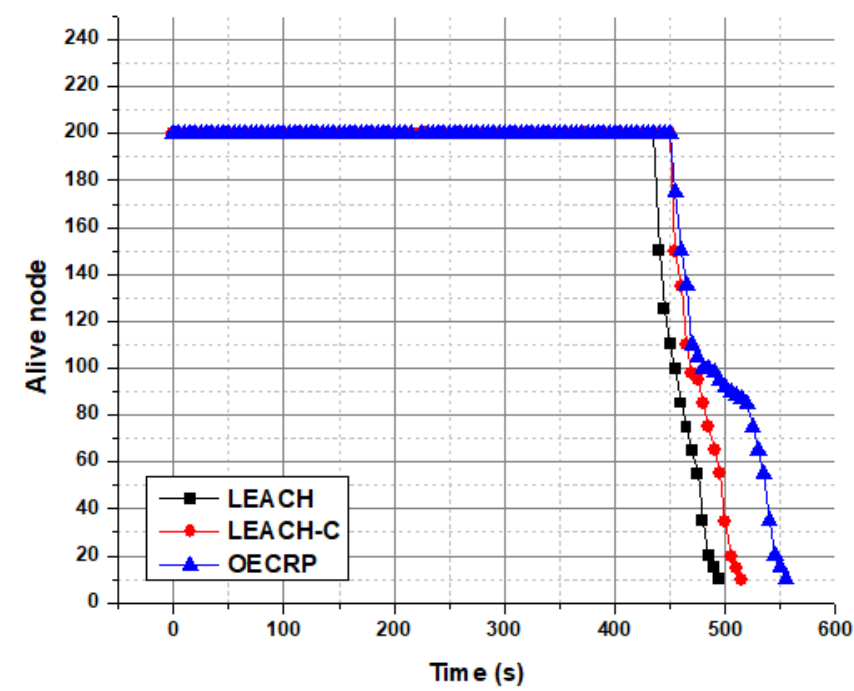

Fig 16. Network lifetime of three methods concerning 200 nodes.

From the Figures 15, 16 and 17, OECRP will have good characteristics with more lifetime of the nodes compared to the other two. The benefit is highly evident in pace along with an increment of node quantity. OECRP convention thinks about what has been specified here just as framing a routing tree depending on the weight of the node. In this situation, regardless of its cluster head or non-cluster head node, the utilization of the energy is more adjusted. It also avoids fewer energy nodes as a cluster head and improves the lifetime of the network.

Table 2 shows the performance analysis of network lifetime and energy consumption of various conventional methods with the proposed method. Figures 18 and 19 shows the analysis and comparison of energy consumption and network lifetime of various methods with the proposed method respectively ${ }^{(49-51)}$. 


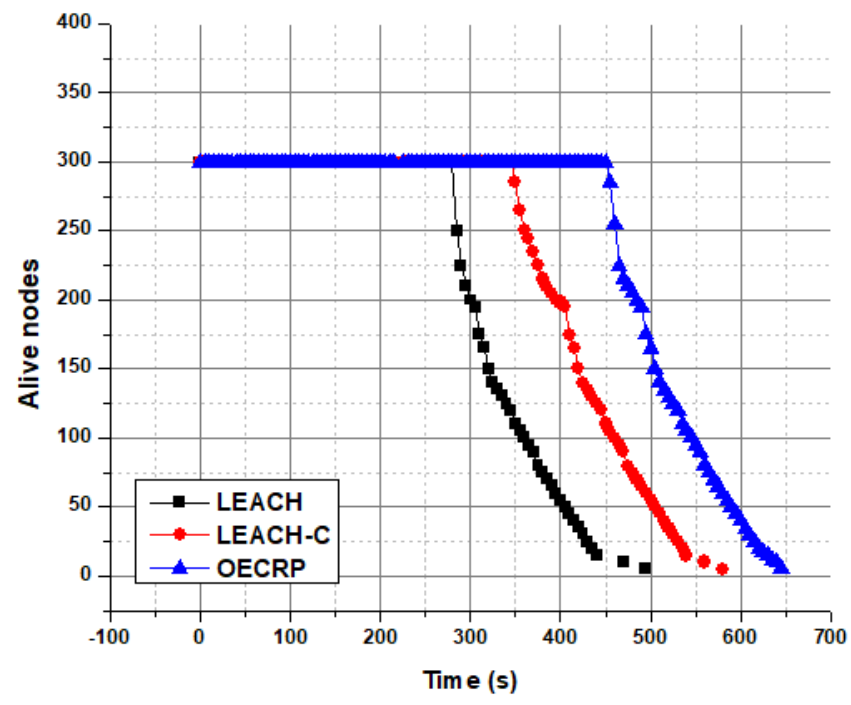

Fig 17. Network lifetime of three methods concerning 300 nodes.

Table 2. performance analysis of energy consumption and network lifetime between conventional methods and the proposed method

\begin{tabular}{|c|c|c|c|c|c|c|c|c|c|}
\hline $\begin{array}{l}\text { SI. } \\
\text { No }\end{array}$ & $\begin{array}{l}\text { Reference } \\
\text { Num- } \\
\text { ber }\end{array}$ & Methods & Protocol & $\begin{array}{l}\text { Numbe } \\
\text { nodes }\end{array}$ & $\begin{array}{l}\text { Cluster head selec- } \\
\text { tion }\end{array}$ & $\begin{array}{l}\text { Communic } \\
\text { method }\end{array}$ & nScalability (\%) & $\begin{array}{l}\text { Network } \\
\text { Life- } \\
\text { time } \\
(\%)\end{array}$ & $\begin{array}{l}\text { Energy } \\
\text { Con- } \\
\text { sumption } \\
(\%)\end{array}$ \\
\hline \multirow[t]{2}{*}{1.} & (8) & \multirow[t]{2}{*}{$\begin{array}{l}\text { Residual } \\
\text { energy }\end{array}$} & LEACH-B & \multirow[t]{2}{*}{200} & $\begin{array}{l}\text { Random, Residual } \\
\text { energy }\end{array}$ & Single hop & $50 \%,($ Good $)$ & 25 & 15 \\
\hline & (52) & & I-LEACH & & Residual energy & Single hop & 75\% (very Good) & 59.04 & 62 \\
\hline \multirow{2}{*}{2.} & (16) & \multirow{2}{*}{ Distance } & BN-LEACH & \multirow{2}{*}{200} & Residual energy & Single hop & $55 \%($ Good $)$ & 52.61 & 28 \\
\hline & (17) & & $\begin{array}{l}\text { Improved- } \\
\text { LEACH }\end{array}$ & & $\begin{array}{l}\text { Distance Residual } \\
\text { energy, }\end{array}$ & Single hop & $56 \%($ Good $)$ & 25 & 32 \\
\hline \multirow{3}{*}{3.} & (18) & \multirow{3}{*}{$\begin{array}{l}\text { Energy } \\
\text { Efficiency }\end{array}$} & TB-LEACH & \multirow{3}{*}{200} & Random & Single hop & 45\% (Limited) & 20 & 55 \\
\hline & (19) & & LEACH-T & & Residual energy & Single hop & $58 \%$ (Good) & 60 & 23 \\
\hline & (21) & & VH-LEACH & & Residual energy & Single hop & $81 \%$ (Very Good) & 59.04 & 41.178 \\
\hline \multirow{2}{*}{4.} & (23) & \multirow{2}{*}{$\begin{array}{l}\text { Single } \\
\text { hop }\end{array}$} & V-LEACH & \multirow{2}{*}{200} & Random & Single hop & $60 \%$ (Good) & 49.37 & 42 \\
\hline & (53) & & W-LEACH & & Random & Single hop & $52 \%$ (Good ) & 60 & 13 \\
\hline \multirow{3}{*}{5.} & (54) & \multirow{3}{*}{$\begin{array}{l}\text { Multi } \\
\text { hop }\end{array}$} & MH-LEACH & \multirow{3}{*}{200} & Random & Multi hop & $57 \%$ (Good ) & 4.57 & 9 \\
\hline & (38) & & $\begin{array}{l}\text { MHT- } \\
\text { LEACH }\end{array}$ & & Random & Multi hop & $59 \%$ (Good) & 77.70 & 69 \\
\hline & (39) & & $\begin{array}{l}\text { IMHT- } \\
\text { LEACH }\end{array}$ & & Random & Multi hop & $61 \%($ Good $)$ & 55.31 & 23 \\
\hline \multirow{6}{*}{6.} & $(40)$ & \multirow{5}{*}{$\begin{array}{l}\text { Single/ } \\
\text { Multi } \\
\text { hop }\end{array}$} & LEACH-TL & \multirow{6}{*}{200} & $\begin{array}{l}\text { Random, Residual } \\
\text { Energy }\end{array}$ & Multi hop & $75 \%$ (Good) & 52.76 & 65 \\
\hline & (41) & & $\begin{array}{l}\text { BRE- } \\
\text { LEACH }\end{array}$ & & Residual energy & Multi hop & $86 \%$ (Very Good) & 55.73 & 55.73 \\
\hline & (44) & & E-LEACH & & Residual energy & Multi hop & $80 \%$ (Very Good) & 49 & 55 \\
\hline & (53) & & L-LEACH & & Random & Multi hop & 79\% (Very Good) & 51 & 22 \\
\hline & (16) & & $\begin{array}{l}\text { EDMHT- } \\
\text { LEACH }\end{array}$ & & Residual energy & Multi hop & 83\% (Very Good) & 88.43 & 25 \\
\hline & Proposed & & $\begin{array}{l}\text { Proposed } \\
\text { OECRP }\end{array}$ & & $\begin{array}{l}\text { Distance, Density, } \\
\text { Residual energy }\end{array}$ & Multi hop & $86 \%$ (Very Good) & 90.25 & 8 \\
\hline
\end{tabular}




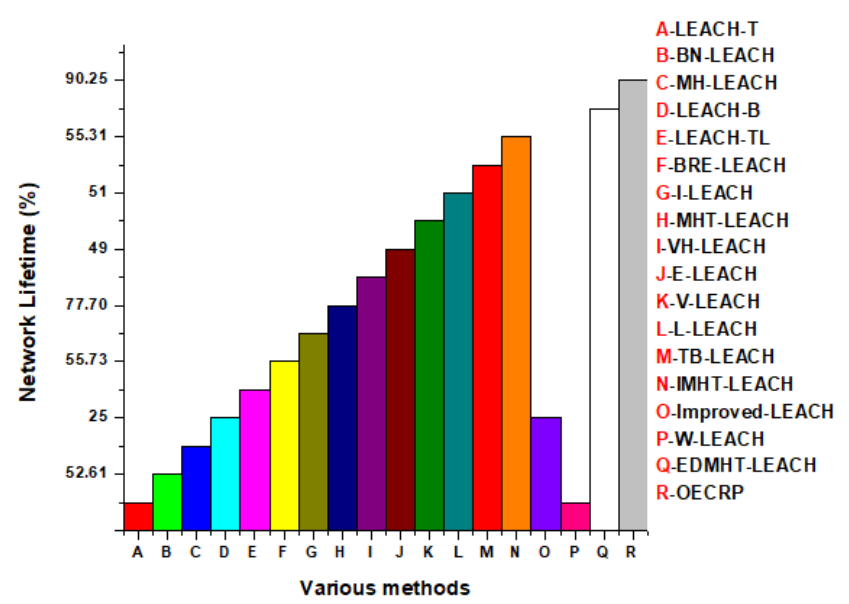

Fig 18. Energy consumption analysis between conventional methods with the proposed method.

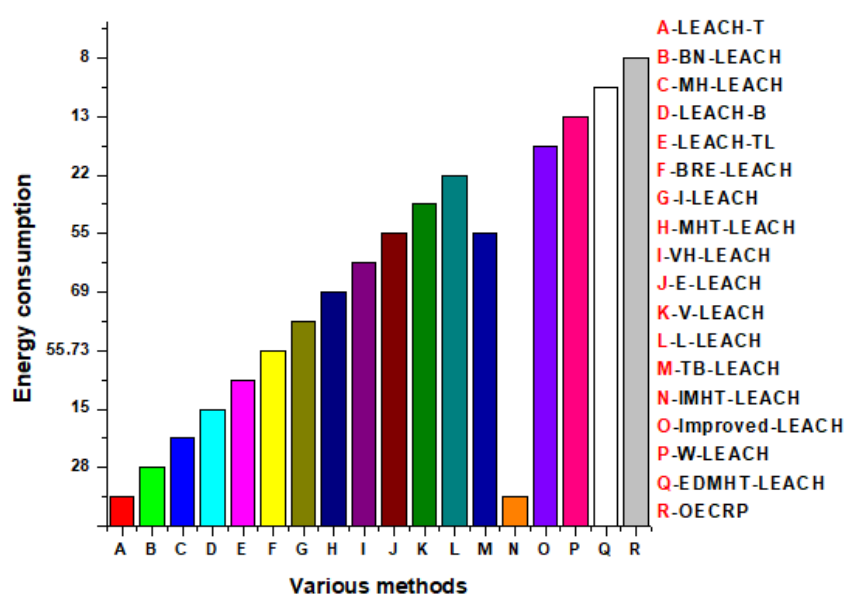

Fig 19. Energy consumption analysis between conventional methods with the proposed method.

\section{Conclusions}

The proposed method monitors more efficiently in a highly confined area such as $150 \mathrm{M} * 150 \mathrm{M}, 200 \mathrm{M} * 200 \mathrm{M}$ and $250 \mathrm{M} * 250$ $\mathrm{M}$ with 200 node density in each monitoring area with improved efficiency of $2.5 \%, 47.5 \%$ and $55 \%$ respectively compared to conventional methods. It enhances $1.82 \%$ network lifetime with respect to 300 nodes and $250 \mathrm{M} * 250 \mathrm{M}$ monitoring area compared to conventional methods. The result clearly shows that the proposed method selects the cluster head with highly optimal path integration between the nodes. Due to this approach, data communication between nodes efficiency increases to 3 $\%$ without creation of any overheads. The proposed OECRP enhances the network lifetime of heterogeneous nodes by analyzing their characteristics in energy levels of $0.8 \mathrm{~J}$ and $2 \mathrm{~J}$. The proposed OECRP resolves the constraint of distance consideration to the formation of cluster heads in the $100 \mathrm{M} * 100 \mathrm{M}$ monitoring area. The proposed topological structure avoids the $21.22 \%$ of energy consumption due to packet loss during data transmission from node to node, node to cluster head, and cluster heads to the base station.

\section{Limitation}

In our proposed research work, there exists some limitations. When more nodes are communicated through the multi-path method in a highly restricted and remote area with high bandwidth in $5 \mathrm{G}$ technologies, there may be a loss of information due 
to attenuation.

\section{Future scope}

The proposed research work helps in further enhancement of this approach in the future. The best-optimized results can be obtained using the optimization algorithm. The proposed work improves stability and wise selection of cluster heads. Image segmentation, artificial image intelligence, digital imaging, optimization can be implemented using this approach.

\section{References}

1) Thiriveni GV, Ramakrishnan M. Distributed Clustering based Energy Efficient Routing Algorithm for Heterogeneous Wireless Sensor Networks. Indian Journal of Science and Technology. 2016;9(3):1-6. Available from: https://dx.doi.org/10.17485/ijst/2016/v9i3/80493.

2) Sheikhpour R, Jabbehdari S. Wireless sensor network, Clustering protocol, Chain based routing, Energy efficient, Time critical data. Indian Journal of Science and Technology. 2012;5(5):1-9. Available from: https://dx.doi.org/10.17485/ijst/2012/v5i5.17.

3) Debasis K, Singh MP, Kumar P, Bhaskar S. Detection of Sybil Nodes in Wireless Sensor Networks. Indian Journal of Science and Technology. 2017;10(3):1-6. Available from: https://dx.doi.org/10.17485/ijst/2017/v10i3/110641.

4) Karpagam M. HEED Protocol using a Cluster based V2V Communication. Indian Journal of Science and Technology. 2019;12(06):1-7. Available from: 10.17485/ijst/2019/v12i6/141891.

5) Gomathi K, Parvathavarthini B. An Enhanced Distributed Weighted Clustering Routing Protocol for Key Management. Indian Journal of Science and Technology. 2015;8(4):342-348. Available from: 10.17485/ijst/2015/v8i4/60435.

6) Priya T, Samuel SJ. Priority based Multi SenCar Technique in Wireless Sensor Networks. Indian Journal of Science and Technology. 2016;9(21):1-6. Available from: https://dx.doi.org/10.17485/ijst/2016/v9i21/95162.

7) Joshi J, Rathoda J, Wandra K. Performance Enhancement of LEACH for Secured Data Transmission. Indian Journal of Science and Technology. 2017;10(20):1-4.

8) Gharghi M. Designing a Fuzzy Rule Base System to Head Cluster Election in Wireless Sensor Networks. Indian Journal of Science and Technology. 2013;6(5):1-6. Available from: https://dx.doi.org/10.17485/ijst/2013/v6i5.4.

9) Khan MN, Jamil M. Performance Improvement in Lifetime and Throughput of LEACH Protocol. Indian Journal of Science and Technology. 2016;9(21):1-6. Available from: https://dx.doi.org/10.17485/ijst/2016/v9i21/94838.

10) Chaitra S, Rekha A, Harisha TA, Madhu S, Mallikarjunaswamy N. A comprehensive review of parallel concatenation of LDPC code techniques. Indian Journal of Science and Technology. 2021;14(5):432-444. Available from: 10.17485/IJST/v14i5.2171.

11) Xu J, Jin N, Lou X, Peng T, Zhou Q, Chen Y. Improvement of LEACH protocol for WSN. 2012 9th International Conference on Fuzzy Systems and Knowledge Discovery. 2012;p. 2174-2177. Available from: 10.1109/FSKD.2012.6233907.

12) Nandan AS, veer Singh S, Awasthi LK. An efficient cluster head election based on optimized genetic algorithm for movable sinks in IoT enabled HWSNs. Applied Soft Computing. 2021;107:1-32. Available from: 10.1016/j.asoc.2021.107318.

13) Singh B, Lobiyal DK. Energy-aware Cluster Head Selection Using Particle Swarm Optimization and Analysis of Packet Retransmissions in WSN. Procedia Technology. 2012;4:171-176. Available from: 10.1016/j.protcy.2012.05.025.

14) Krishnaswamy V, Manvi SS. Fuzzy and PSO Based Clustering Scheme in Underwater Acoustic Sensor Networks Using Energy and Distance Parameters. Springer Science+Business Media. 2019;108(3):1529-1546. Available from: 10.1007/s11277-019-06483-y.

15) Satish P, Srikantaswamy M, Ramaswamy NK. Nataraj Kanathur Ramaswamy "A Comprehensive Review of Blind Deconvolution Techniques for Image Deblurring. Traitement du Signal. 2020;37(3):527-539. Available from: 10.18280/ts.370321.

16) Kumar TVUK, Karthik B. Improving Network Life Time using Static Cluster Routing for Wireless Sensor Networks. Indian Journal of Science and Technology. 2013;6(5):1-6. Available from: https://dx.doi.org/10.17485/ijst/2013/v6isp5.12.

17) Sirisha G, Babu RB, Rao KR. Establishing Path Quality Management in Wireless Sensor Networks through Cluster Head Determination. Indian Journal of Science and Technology. 2016;9(5):1-9. Available from: https://dx.doi.org/10.17485/ijst/2016/v9i5/84916.

18) Rafsanjani MK, laya Aliahmadipour, Javidi MM. A hybrid intrusion detection by game theory approaches in MANET. Indian Journal of Science and Technology. 2012;5(2):1-9. Available from: https://dx.doi.org/10.17485/ijst/2012/v5i2.9.

19) Gopinath S, Nagarajan N. An Optimized Multicast Backbone Routing for Increasing Residual Energy in MANET. Indian Journal of Science and Technology. 2015;8(13):1-9. Available from: https://dx.doi.org/10.17485/ijst/2015/v8i13/52303.

20) Kumar R, Singh G, Gaba GS. An Effective Approach for Minimizing Energy Consumption in WSN. Indian Journal of Science and Technology. 2016;9(21):15. Available from: https://dx.doi.org/10.17485/ijst/2016/v9i21/86612.

21) Nandalal V, Sumalatha MS, Kumar V, Kumar CS. Trust Aware Energy Efficient Clustering for Secure Packet Transmission in Wireless Sensor Networks. Indian Journal of Science and Technology. 2019;12(23):1-8. Available from: 10.17485/ijst/2019/v12i23/145375.

22) Vijayan K, Raaza A. A Novel Cluster Arrangement Energy Efficient Routing Protocol for Wireless Sensor Networks. Indian Journal of Science and Technology. 2016;9(2):1-9. Available from: https://dx.doi.org/10.17485/ijst/2016/v9i2/79073.

23) Munusamy K, Parvathi RMS, Chandramohan K. Least Power Adaptive Hierarchy Cluster Framework for Wireless Sensor Network using Frequency Division Multiplexing Channelization. Indian Journal of Science and Technology. 2016;9(6):1-10. Available from: https://dx.doi.org/10.17485/ijst/2016/ v9i6/80046.

24) Umbreen S, Shehzad D, Shaf N, Khan B. An Energy-Efficient Mobility-Based Cluster Head Selection for Lifetime Enhancement of Wireless Sensor Networks. IEEE Access. 2020;8:207779 -207793. Available from: 10.1109/ACCESS.2020.3038031.

25) Lee JY, Jung KD, Moon SJ, Jeong HY. Improvement on LEACH protocol of a wide-area wireless sensor network. Multimedia Tools and Applications volume. 2017;76:19843-19860. Available from: https://doi.org/10.1007/s11042-016-3732-4.

26) Hassan AAH, Shah WM, Habeb AHH, Othman MFI. An Improved Energy-Efficient Clustering Protocol to Prolong the Lifetime of the WSN-Based IoT. IEEE Access. 2020;8:200500 -200517. Available from: 10.1109/ACCESS.2020.3035624.

27) Duarte FL, de Lamare RC. C-RAN-type Cluster-Head-Driven UAV Relaying with Recursive Maximum Minimum Distance. IEEE Communications Letters. 2020;24(11):2623-2627. Available from: 10.1109/LCOMM.2020.3009845. 
28) Neto JHB, da Silva Rego A, Cardoso AR, Jr JC. MH-LEACH: A Distributed Algorithm for Multi-Hop Communication in Wireless Sensor Networks. ICN 2014: The Thirteenth International Conference on Networks. 2014;p. 55-61.

29) Qingjian Ni QP, Du H, Cao C, Zhai Y. A Novel Cluster Head Selection Algorithm Based on Fuzzy Clustering and Particle Swarm Optimization. IEEE/ACM Transactions on Computational Biology and Bioinformatics. 2017;4(1):76-84. Available from: 10.1109/TCBB.2015.2446475.

30) Pavithra GS, Babu NV. Energy efficient hierarchical clustering using HACOPSO in wireless sensor networks. International Journal of Innovative Technology and Exploring Engineering. 2019;8(12).

31) Xiuzhang $\mathrm{X}, \mathrm{Lu}$. Mobile wireless sensor network lifetime maximization by using evolutionary computing methods. Ad Hoc Networks. 2020;101:1-13. Available from: 10.1016/j.adhoc.2020.102094.

32) Tam NT, Binh HTT, Dat VT, Lan PN, Vinh LT. Towards optimal wireless sensor network lifetime in three dimensional terrains using relay placement metaheuristics. Knowledge-Based Systems. 2020;206(106407). Available from: https://dx.doi.org/10.1016/j.knosys.2020.106407.

33) Hao X, Wang L, Yao N, Geng D, Chen B. Topology control game algorithm based on Markov lifetime prediction model for wireless sensor network. Ad Hoc Networks. 2018;78:1-18. Available from: 10.1016/j.adhoc.2018.05.006.

34) Hassan A, Anter A, Kayed M. A robust clustering approach for extending the lifetime of wireless sensor networks in an optimized manner with a novel fitness function. Sustainable Computing: Informatics and Systems. 2021;30(100482). Available from: https://dx.doi.org/10.1016/j.suscom.2020.100482.

35) Keskin ME, Yiğit V. Maximizing the lifetime in wireless sensor networks with multiple mobile sinks having nonzero travel times. Computers \& Industrial Engineering. 2020;148(106719). Available from: https://dx.doi.org/10.1016/j.cie.2020.106719.

36) Shah B, Abbas A, Ali G, Iqbal F, Khattak AM, Alfandi O, et al. Guaranteed lifetime protocol for IoT based wireless sensor networks with multiple constraints. Ad Hoc Networks. 2020;104:1-10. Available from: https://dx.doi.org/10.1016/j.adhoc.2020.102158.

37) Nguyen L, Nguyen HT. Mobility based network lifetime in wireless sensor networks: A review. Computer Networks. 2020;174:1-36. Available from: https://dx.doi.org/10.1016/j.comnet.2020.107236.

38) Sharma D, Tomar GS. Enhance PEGASIS Algorithm for Increasing the Life Time of Wireless Sensor Network. Materials Today: Proceedings. 2020;29:372380. Available from: https://dx.doi.org/10.1016/j.matpr.2020.07.291.

39) Ghosal A, Halder S, Das SK. Distributed on-demand clustering algorithm for lifetime optimization in wireless sensor networks. Journal of Parallel and Distributed Computing. 2020;141:1-36. Available from: 10.1016/j.jpdc.2020.03.014.

40) Guimarães DA, Frigieri EP, Sakai LJ. Influence of node mobility, recharge, and path loss on the optimized lifetime of wireless rechargeable sensor networks. Ad Hoc Networks. 2020;97:1-29. Available from: https://dx.doi.org/10.1016/j.adhoc.2019.102025.

41) Kia G, Hassanzadeh A. A multi-threshold long life time protocol with consistent performance for wireless sensor networks. AEU - International Journal of Electronics and Communications. 2019;101:114-127. Available from: https://dx.doi.org/10.1016/j.aeue.2019.01.034.

42) Luo C, Hong Y, Li D, Wang Y, Chen W, Hu Q. Maximizing network lifetime using coverage sets scheduling in wireless sensor networks. Ad Hoc Networks. 2020;98:1-16. Available from: https://dx.doi.org/10.1016/j.adhoc.2019.102037.

43) Elkamel R, Messouadi A, Cherif A. Extending the lifetime of wireless sensor networks through mitigating the hot spot problem. Journal of Parallel and Distributed Computing. 2019;133:159-169. Available from: https://dx.doi.org/10.1016/j.jpdc.2019.06.007.

44) Sharma H, Haque A, Jaffery ZA. Maximization of wireless sensor network lifetime using solar energy harvesting for smart agriculture monitoring. Ad Hoc Networks. 2019;94:1-25. Available from: https://dx.doi.org/10.1016/j.adhoc.2019.101966.

45) Khalily-Dermany M, Nadjafi-Arani MJ, Doostali S. Combining topology control and network coding to optimize lifetime in wireless-sensor networks. Computer Networks. 2019;162:1-41. Available from: https://dx.doi.org/10.1016/j.comnet.2019.106859.

46) Kang SH, Nguyen T. Distance Based Thresholds for Cluster Head Selection in Wireless Sensor Networks. IEEE Communications Letters. 2012;16(9):1396 -1399. Available from: 10.1109/LCOMM.2012.073112.120450.

47) Choudhury N, Matam R, Mukherjee M, Lloret J, Kalaimannan E. NCHR: A Nonthreshold-Based Cluster-Head Rotation Scheme for IEEE 802.15.4 Cluster-Tree Networks. IEEE Internet of Things Journal. 2021;8(1):168-178. Available from: https://dx.doi.org/10.1109/jiot.2020.3003320. doi:10.1109/jiot.2020.3003320.

48) Choi HH, Muy S, Lee JR. Geometric Analysis-Based Cluster Head Selection for Sectorized Wireless Powered Sensor Networks. IEEE Wireless Communications Letters. 2021;10(3):649 -653. Available from: 10.1109/LWC.2020.3044902.

49) Jia D, Zhu H, Zou S, Hu P. Dynamic Cluster Head Selection Method for Wireless Sensor Network. IEEE Sensors Journal. 2016;16(8):2746-2754. Available from: https://dx.doi.org/10.1109/jsen.2015.2512322. doi:10.1109/jsen.2015.2512322.

50) Tselikis C, Mitropoulos S, Komninos N, Douligeris C. Degree-Based Clustering Algorithms for Wireless Ad Hoc Networks Under Attack. IEEE Communications Letters. 2012;16(5):619-621. Available from: https://dx.doi.org/10.1109/lcomm.2012.031912.112484. doi:10.1109/lcomm.2012.031912.112484.

51) Ali H, Tariq UU, Hussain M, Lu L, Panneerselvam J, Zhai X. ARSH-FATI: A Novel Metaheuristic for Cluster Head Selection in Wireless Sensor Networks. IEEE Systems Journal. 2021;15(2):2386-2397. Available from: https://dx.doi.org/10.1109/jsyst.2020.2986811. doi:10.1109/jsyst.2020.2986811.

52) Leu JS, Chiang TH, Yu MC, Su KW. Energy Efficient Clustering Scheme for Prolonging the Lifetime of Wireless Sensor Network With Isolated Nodes. IEEE Communications Letters. 2015;19(2):259-262. Available from: https://dx.doi.org/10.1109/lcomm.2014.2379715. doi:10.1109/lcomm.2014.2379715.

53) Calabuig D, Martin-Sacristan D, Monserrat JF, Botsov M, Gozalvez D. Distribution of Road Hazard Warning Messages to Distant Vehicles in Intelligent Transport Systems. IEEE Transactions on Intelligent Transportation Systems. 2018;19(4):1152-1165. Available from: https://dx.doi.org/10.1109/tits.2017. 2718103. doi:10.1109/tits.2017.2718103.

54) Zhao M, Yang Y, Wang C. Mobile Data Gathering with Load Balanced Clustering and Dual Data Uploading in Wireless Sensor Networks. IEEE Transactions on Mobile Computing. 2015;14(4):770-785. Available from: https://dx.doi.org/10.1109/tmc.2014.2338315. doi:10.1109/tmc.2014.2338315. 